\title{
Snub-nosed monkeys (Rhinopithecus): potential distribution and its implication for conservation
}

\author{
Jonas Nüchel $^{1,2}$ (D) Peder Klith Bøcher $^{1} \cdot$ Wen Xiao $^{3} \cdot$ A-Xing Zhu ${ }^{4,5,6}$. \\ Jens-Christian Svenning, ${ }^{1,7}$
}

Received: 2 October 2016 / Revised: 9 January 2018 / Accepted: 17 January 2018 /

Published online: 23 January 2018

(C) The Author(s) 2018. This article is an open access publication

\begin{abstract}
Many threatened species have undergone range retraction, and are confined to small fragmented populations. To increase their survival prospects, it is necessary to find suitable habitat outside their current range, to increase and interconnect populations. Species distribution models may be used to this purpose and can be an important part of the conservation strategies. One pitfall is that such mapping will typically assume that the current distribution represents the optimal habitat, which may not be the case for threatened species. Here, we use maximum entropy modelling (Maxent) and rectilinear bioclimatic envelope modelling with current and historical distribution data, together with the location of protected areas, and environmental and anthropogenic variables, to answer three key questions for the conservation of Rhinopithecus, a highly endangered genus of primates consisting of five species of which three are endemic to China, one is endemic to China
\end{abstract}

Communicated by David Hawksworth.

Electronic supplementary material The online version of this article (https://doi.org/10.1007/s105 31-018-1507-0) contains supplementary material, which is available to authorized users.

Jonas Nüchel

j.nuchel@bios.au.dk; j.nychel@live.com

1 Section for Ecoinformatics \& Biodiversity, Department of Bioscience, Aarhus University, Ny Munkegade 114, 8000 Aarhus, Denmark

2 Sino-Danish Center for Education and Research, Beijing 100101, China

3 Institute of Eastern-Himalaya Biodiversity Research, Dali University, Dali 671003, Yunnan, China

4 School of Geography, Nanjing Normal University, Nanjing 210023, Jiangsu, China

5 State Key Laboratory of Resources and Environmental Information System, Institute of Geographical Sciences and Natural Resources Research, Chinese Academy of Sciences, Beijing 100101, China

6 Department of Geography, University of Wisconsin-Madison, 550 North Park Street, Madison, WI 53706, USA

7 Center for Biodiversity Dynamics in a Changing World (BIOCHANGE), Aarhus University, Ny Munkegade 114, 8000 Aarhus, Denmark 
and Myanmar and one is endemic to Vietnam; Which environmental variables best predict the distribution? To what extent is Rhinopithecus living in an anthropogenically truncated niche space? What is the genus' potential distribution in the region? Mean temperature of coldest and warmest quarter together with annual precipitation and precipitation during the driest quarter were the variables that best explained Rhinopithecus' distribution. The historical records were generally in warmer and wetter areas and in lower elevation than the current distribution, strongly suggesting that Rhinopithecus today survives in an anthropogenic truncated niche space. There is $305,800-319,325 \mathrm{~km}^{2}$ of climatic suitable area within protected areas in China, of which $96,525-100,275 \mathrm{~km}^{2}$ and $17,175-17,550 \mathrm{~km}^{2}$ have tree cover above 50 and $75 \%$, respectively. The models also show that the area predicted as climatic suitable using Maxent was $72-89 \%$ larger when historical records were included. Our results emphasise the importance of considering historical records when assessing restoration potential and show that there is high potential for restoring Rhinopithecus to parts of its former range.

Keywords Rhinopithecus $\cdot$ Snub-nosed monkey $\cdot$ Species distribution modelling · Historical distribution $\cdot$ Maxent $\cdot$ Conservation

\section{Introduction}

Around $28 \%$ of mammal species are threatened or near threatened with extinction (IUCN 2014). The main threats are habitat loss and habitat degradation, mainly due to anthropogenic pressure, and many species have had their ranges reduced and are today living in small fragmented populations (IUCN 2008; Schipper et al. 2008). These species are therefore more vulnerable to further anthropogenic impacts, with the small population size also itself constituting a threat, causing vulnerability to inbreeding, demographic stochasticity, diseases and catastrophes (Caughley 1994). One of the main conservation tools is protecting the existing habitat which threatened species inhabit (Joppa and Pfaff 2011; Juffe-Bignoli et al. 2014). However, for species surviving only as small and fragmented populations this may not be sufficient to ensure their survival. Hence, reintroduction may be used to help enhance the long-term survival prospects for these species, by translocation of species to suitable habitat outside its current range, for example previously occupied areas. Additionally, such reintroductions or otherwise assisted range expansions will be necessary to restore the ecological functions of such species (Seddon et al. 2014; Svenning et al. 2016).

Species distribution modelling (SDM) can be used to find potential or suitable habitat outside the species current range, (e.g. Morueta-Holme et al. 2010; Kuemmerle et al. 2011; Chatterjee et al. 2012; Naundrup and Svenning 2015). Many SDMs use only the current distribution of the species and assume that the habitat within represents the best habitat (Braunisch et al. 2008). However, many threatened species have undergone range decline and might be refugee species, i.e., confined to living in suboptimal habitat due to anthropogenic pressures (Kerley et al. 2012). In such cases, SDM, if based on current data from refugee habitats, might misguide conservation management by assuming that remnant populations are found in the most favourable habitat (Cromsigt et al. 2012).

East Asia in general has high biodiversity, e.g. China ranks third in the world in total number of mammal species (IUCN 2008; Smith and Xie 2008), it has a higher diversity of species than either North America or Europe and around one-eighth of all know species on earth (Harkness 1998). Unfortunately, the region also has a high proportion of threatened 
mammals (Schipper et al. 2008; Hoffmann et al. 2010). China has a long history of anthropogenic impacts on its ecosystems and the impacts have grown drastically in the recent century and especially the last decades, e.g. large areas of forest have been logged during the last half century and the population in China has also more than doubled in the same period (Harkness 1998; Liu and Diamond 2005). This also means that there is a high probability that many of the regions' threatened species are refugee species, confined to suboptimal habitat. On the other hand, it should be noted that there are large reforestation and afforestation programs going on in China, especially since end of 1990s (Yin et al. 2005; Zhang and Song 2006; Peng et al. 2014; Nüchel and Svenning 2017).

One of the organism groups with many threatened species are primates. Of the 508 known species of primates world-wide, 437 have been assessed by the International Union for Conservation of Nature (IUCN) Red List and of these are more than 66\% threatened or near-threatened (IUCN 2016) and the primates in South and Southeast Asia has an even more precarious conservation status, with around 79\% threatened with extinction (Schipper et al. 2008). In this study, we focus on one group of East Asian threatened primates, the snub-nosed monkeys (Rhinopithecus), comprising five species: Rhinopithecus bieti (black (Yunnan) snub-nosed monkey), R. brelichi (grey (Guizhou) snub-nosed monkey), $R$. roxellana (golden (Sichuan) snub-nosed monkey), R. strykeri (Myanmar (Burmese) snubnosed monkey) and $R$. avunculus (Tonkin snub-nosed monkey). All five species are listed as endangered or critically endangered on the IUCN Red List, with all having decreasing populations. Furthermore, $R$. brelichi, $R$. strykeri and $R$. avunculus are, with total population sizes under 1000 individuals, on the brink of extinction (Bleisch et al. 2008; Bleisch and Richardson 2008; Xuan Canh et al. 2008; Yongcheng and Richardson 2008; Liu et al. 2009; Xiang et al. 2009; Geissmann et al. 2012). However, while the distribution of Rhinopithecus is small and fragmented today, fossil and historical records show that it historically has been widely distributed across South, East and Central China (Kirkpatrick 1995; Li et al. 2002).

The main threats for all five species are habitat loss and hunting (Bleisch et al. 2008; Bleisch and Richardson 2008; Xuan Canh et al. 2008; Yongcheng and Richardson 2008; Geissmann et al. 2012). In addition, future climate changes and increases in human population and resource demand will likely increase pressure on all Rhinopithecus populations. All Rhinopithecus species therefore face an uncertain future, and to increase their survival chances it is necessary to increase their population size and distributions.

In this study, we use species distribution modelling to identify which climatic factors are associated with the current distribution of Rhinopithecus within East Asia. We then assess the extent to which Rhinopithecus are refugee species, confined to an anthropogenically truncated niche space (Cromsigt et al. 2012), by incorporating historical records of extirpated populations within the SDM. Finally, to identify areas that may be suitable for reintroduction, we estimate the potential distribution of Rhinopithecus within the region, considering climate, habitat availability and the locations of nature reserves.

\section{Methods}

\section{Study region and distribution data}

We used range maps from the International Union for Conservation of Nature (IUCN) for all five Rhinopithecus species as current distribution data (IUCN 2014). We converted the 
IUCN polygons to $5 \times 5 \mathrm{~km}$ grid cells and then to one point per cell (centre of grid). The range estimates were refined by excluding all points outside the species' known elevation ranges, which are between 200 and $1200 \mathrm{~m}$ for $R$. avunculus (Xuan Canh et al. 2008), 570 and $2300 \mathrm{~m}$ for $R$. brelichi (Bleisch et al. 2008), 1400 and $2800 \mathrm{~m}$ for $R$. roxellana (Yongcheng and Richardson 2008), 1720 and $3190 \mathrm{~m}$ for R. strykeri (Geissmann et al. 2012), and 3000 and $4700 \mathrm{~m}$ for R. bieti (Bleisch and Richardson 2008). Furthermore, we also excluded all areas with tree cover below $50 \%$, all areas with human population density above 100 and/or all areas with values above 20 on the human influence index (HII) (see next section for explanation of HII). Afterwards, to reduce spatial bias, we used Occurrence Thinner version 1.04 (Verbruggen 2012; Verbruggen et al. 2013) to thin the points, so we had 142 occurrence points within the IUCN ranges. In addition, historical records for historically extirpated populations of Rhinopithecus in China were acquired from Li et al. (2002). By digitalizing maps from Li et al. (2002), we derived 96 approximate locations for historical records from 1616 to 1949, including 70 locations outside the current range of the genus (Fig. 1).

The range data for all Rhinopithecus species were combined in most of our modelling (i.e., modelling Rhinopithecus as a single taxon), mainly as the historical records could not be identified into species level, but also to overcome niche truncation. All Rhinopithecus species, with the exception of $R$. avunculus, occur in subtropical to temperate forest (see Supporting Information Appendix S1 for map of ecoregions/vegetation zones) and

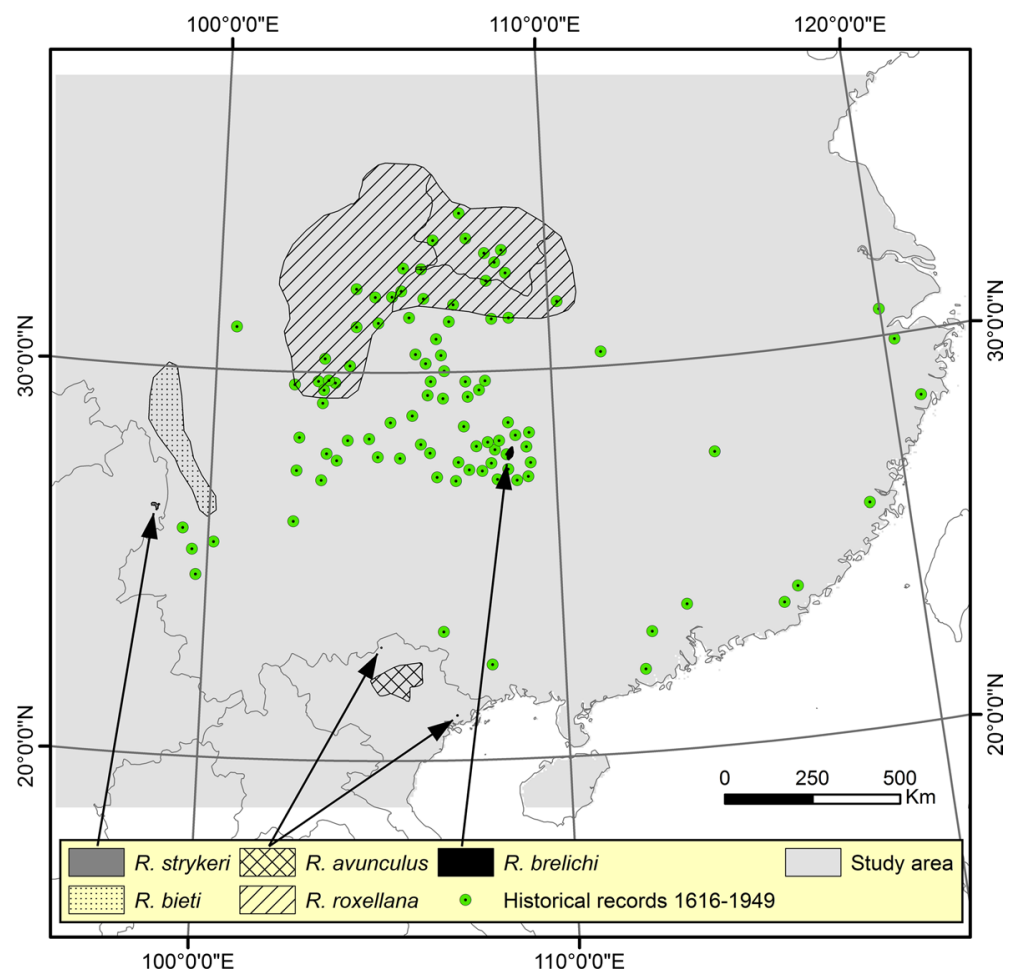

Fig. 1 Distribution of Rhinopithecus. IUCN range maps for all five species (R. strykeri, R. avunculus, $R$. brelichi, $R$. roxellana \& $R$. bieti) and historical records from 1616 to 1949 
hence may be hypothesized to have similar ecological requirements. Rhinopithecus bieti, $R$. strykeri, $R$. brelichi and $R$. roxellana mainly occur in mixed deciduous and evergreen broadleaf forest, with $R$. bieti, $R$. strykeri, and $R$. roxellana also occuring in coniferous forest, and $R$. avunculus most deviant, being found in tropical evergreen forest (Bleisch et al. 2008; Bleisch and Richardson 2008; Xuan Canh et al. 2008; Yongcheng and Richardson 2008; Geissmann et al. 2012). Furthermore, Rhinopithecus has a high dietary plasticity and occur in areas that have large variations in climate between summer and winter (Long et al. 1994; Yiming 2006; Guo et al. 2007; Xiang et al. 2007b, 2012; Grueter et al. 2009a; Wong et al. 2013). Additionally, we also know that at least some of the species had a more wider distributions as late as within the last 400 years ( $\mathrm{Li}$ et al. 2002), also in areas that are more climatic different than possibly unoccupied areas within the IUCN polygons. Moreover, as stated in the introduction, some threatened species might be refugee species living in suboptimal habitats (Kerley et al. 2012; Cromsigt et al. 2012) and the current range might not show their full climatic suitable range.

The study area includes a part of East Asia, including areas in China, Myanmar and Vietnam where Rhinopithecus are known to occur (Fig. 1). The study area was delimited by drawing a rectangle around a 500-km buffer outside the species range maps and historical occurrence points.

\section{Environmental and anthropogenic data}

Multiple models were calibrated to identify which climate variables are most strongly associated with the distribution of the genus. Initially, eight climatic variables from the WorldClim database (Hijmans et al. 2005) were considered; (1) annual mean temperature (AMT), (2) mean temperature of warmest quarter (MTWQ), (3) mean temperature of coldest quarter (MTCQ), (4) minimum temperature of coldest month (MinTCM), (5) annual precipitation (PANN), (6) precipitation of wettest quarter (PWetQ), (7) precipitation of driest quarter (PDryQ), (8) precipitation of coldest quarter (PColdQ). The four temperature variables, PANN, PDryQ and PWetQ were chosen due to their effect on vegetation and thereby habitat. PColdQ was chosen because the monkeys, except $R$. avunculus and to some degree $R$. brelichi, mainly live in high elevations and precipitation during the coldest quarter will extensively fall as snow and possible limit the food availability.

The historical records for extirpated populations of Rhinopithecus were mainly located in Central East (CE) and Southeast (SE) China. We note that the temperature has varied within the period of the historical records (1616-1949) and also subsequently up to the present-day. Generally, the climate was colder in the period of the historical records, with a maximum temperature difference between the coldest period (around 1660 and again around 1840) and current temperature of $1.8^{\circ} \mathrm{C}$ for CE China and $1.2{ }^{\circ} \mathrm{C}$ for SE China on a decadal time series, and $0.7^{\circ} \mathrm{C}$ for $\mathrm{CE}$ China and $0.6^{\circ} \mathrm{C}$ for SE China on a centennial time series (Ge et al. 2013). To investigate the possible effect of these temperature shifts and, specifically, the colder period during the time of the historical records, we performed a temperature sensitivity analysis by decreasing the current temperature with different magnitudes, subtracting $0.7,1.5$ and $2.0{ }^{\circ} \mathrm{C}$, respectively, from each of the current temperature variables before calibrating the distribution models. The down-adjusted climate variables were used to assess the sensitivity of the models to the different climate and compare the results between models with different adjusted climate data.

Furthermore, we used topographic data from Shuttle Radar Topography Mission (SRTM) (Jarvis et al. 2008) for elevation (ELEV), and computed slope (Slope), standard deviation (STD), and topographic roughness (slope of slope) (TR). Data for protected areas 
in China were derived from World Database on Protected Areas (IUCN and UNEP-WCMC 2014) and to capture tree cover we used the Moderate Resolution Imaging Spectroradiometer (MODIS) Vegetation Continuous Fields from 2010 (DiMiceli et al. 2011).

We used two different measures of anthropogenic pressure to refine our current distribution data; human population density for 2010 (CIESIN 2015) and the Human Influence Index (HII) (WCS and CIESIN 2005). HII is an index going from 0 (no impact) to 64 (maximum impact) that combines data for population density with data for human land use and accessibility (roads, railroads, navigable rivers and coastlines) and can be used to describe anthropogenic impacts on the environment. The refining was done by excluding all areas within the IUCN range maps with human population density above 100 and/or all areas with values above 20 on the HII.

All data were projected to the Albers Equal Area Conic projection, and converted to their mean values for $5 \mathrm{~km} \times 5 \mathrm{~km}$ grid cells. ArcGIS 10.2 (ESRI, Redlands, CA) was used for all GIS operations.

\section{Maximum entropy modelling/distribution modelling}

One of the modelling method used was Maximum entropy modelling (Maxent version 3.3.3k (http://www.cs.princeton.edu/ schapire/maxent/), which is a machine learning method for mapping habitat suitability or estimate the potential distribution of a species (Phillips et al. 2006; Phillips and Dudík 2008; Elith et al. 2011). Maximum entropy modelling is among the best-performing methods for species distribution modelling and frequently outperforms traditional statistical approaches and other species distribution modelling methods (Elith et al. 2006; Phillips et al. 2006).

Pairwise Pearson's correlation coefficients (r) for all variables over the entire study area were calculated (see Supporting Information Appendix S2 for $r$ values) to quantify collinearity. Although Maxent is relatively robust against collinear variables, collinearity can impair the estimation of the influence of individual variables on the model. Among the climatic variables AMT was highly correlated with MinTCM $(r=0.98)$, MTWQ $(r=0.92)$, and MTCQ $(r=0.96)$. AMT contributed less to the predictive power than MinTCM and MTCQ, and was therefore not included in the modelling. Furthermore, MinTCM and MTCQ were also highly correlated $(\mathrm{r}=0.98)$ and were consequently only included in mutually exclusive models. MTWQ was also correlated with MTCQ $(r=0.78)$ and MinTCM $(r=0.85)$. MTWQ did not explain much of the variance, but provided a small increase in predictive power and was therefore kept in four of the final models (Table 1). PWetQ was strongly correlated with PANN ( $\mathrm{r}=0.94)$, with PANN contributing more to predictive power than PWetQ; therefore PWetQ was removed. PDryQ and PColdQ were also correlated $(\mathrm{r}=0.98)$ and contributed almost equally to the predictive power. PDryQ indicate the minimum amount of precipitation for a quarter and can be more of an indirect stress factor for vegetation than PColdQ. Therefore, PColdQ was consequently removed.

Out of the four topographic variables, only ELEV contributed a little to the overall predictive power, with the rest having no influence at all. ELEV, STD, Slope and TR were consequently left out of the final models. Both measure for anthropogenic pressure, human population density for 2010 and HII were also left out of our final models, so our final models only model climatic suitability (see Supporting Information Appendix S3, S4 and result section for further).

The final variables in the models were PANN, PDryQ, MTWQ, and MinTCM or MTCQ. This resulted in a total of four models, which were run with current distribution 


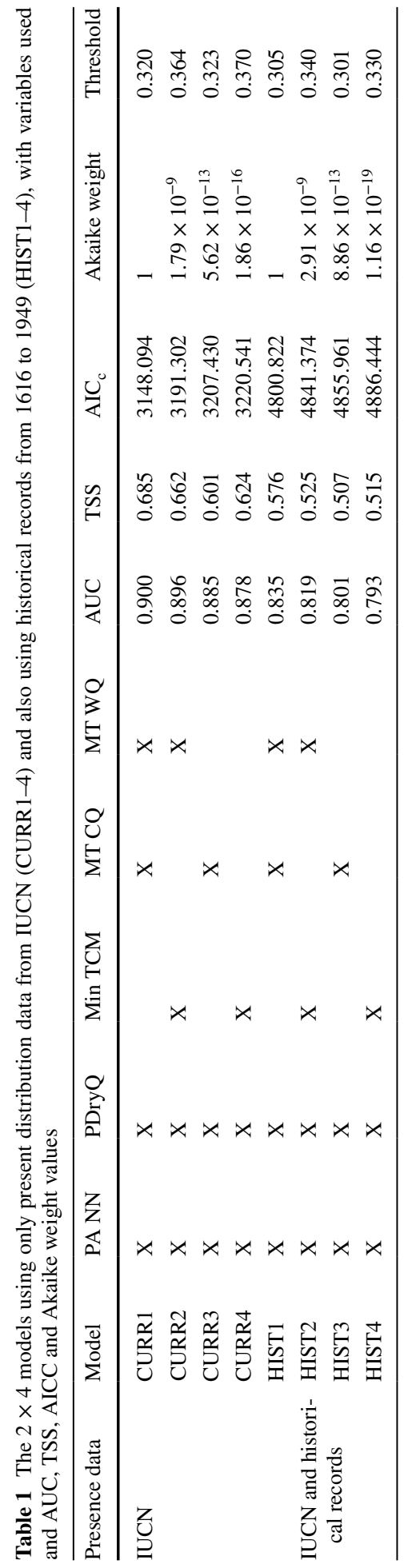


data derived from the IUCN ranges and also with both current distribution data and historical records from 1616 to 1949 (Table 1).

\section{Model tuning and evaluation}

We used area under the curve (AUC) of the receiver operating characteristics (ROC) curve to estimate the predictive power of our models. The maximum AUC value is 1, achieved by perfect discrimination between occupied and non-occupied cells, while a model with no better predictive ability than random choice will result in an AUC value of 0.5. In practice, models with an AUC above 0.75 are considered potentially useful (Phillips and Dudík 2008). We note that for presence-only data, like in the present study, the highest achievable AUC is $<1$ (Phillips et al. 2006).

AUC values may not always be the optimal method to evaluate model performance, e.g. as AUC weighs omission and commission errors equally, and the geographical extent to which models are carried out in can highly influences the AUC values (Lobo et al. 2008). Therefore, the models were also evaluated using the true skill statistic (TSS), which in contrast to kappa is independent of prevalence (Allouche et al. 2006). TSS uses the same scale as kappa and has values between 0 and 1 , where $0-0.4=$ poor, $0.4-0.5=$ fair, $0.5-0.7=$ good. $0.7-0.85=$ very good, $0.85-0.9=$ excellent and $0.9-1=$ perfect.

In addition to TSS and AUC, we used the R package ENMeval version 0.1.1 (Muscarella et al. 2014) to tune the features and regularization multiplier settings in Maxent, and ENMTools version 1.4.4 (Warren et al. 2008, 2010) to calculate the sample size corrected Akaike Information Criterion $\left(\mathrm{AIC}_{\mathrm{C}}\right)$ and Akaike weights value for our models. $\mathrm{AIC}_{\mathrm{C}}$ has been showed to outperform AUC-based methods for model selection in many cases (Warren and Seifert 2010). The final models were run using default settings, except the regularization multiplier value, which was set to 2.5, maximum iterations was changed to 5,000 and all features were used. To derive suitability and predictive maps the final models were run 10 times with cross validate as replicated run type.

\section{Suitable habitat and potential distribution}

Our predictive presence-absence map was derived using the 10th percentile training presence thresholds, which selects the value above which $90 \%$ of the training samples are correctly classified. Selection of the best thresholds can be difficult and depends on the sample size and the purpose of the study (Pearson et al. 2004; Liu et al. 2005; Freeman and Moisen 2008; Bean et al. 2012), but in general maximum training sensitivity and specificity, and equal training and specificity perform best (Jiménez-Valverde and Lobo 2007; Liu et al. 2013; Cao et al. 2013). The above thresholds are more conservative thresholds than the minimum training presence threshold, which correctly predicts every training sample (See Supporting Information Appendix S5 for a comparison of thresholds effect on our predictive presence-absence map). As an alternative, which is better protected against overfitting, we also generated a rectilinear bioclimatic envelope model, defined as areas within minimum and maximum values of the five climatic variables, PANN, PDryQ, MinTCM, MTCQ and MTWQ, using only current distribution data derived from IUCN ranges and using both current distribution data and historical records, in ArcGIS. We did this for all species combined and also for each species separately. The latter was done to compare the species- and genus-level results, mainly for checking their consistency. Furthermore, the models with current and historical distribution data were modelled using both current 
climate data and current climate data adjusted with $-0.7,-1.5$, and -2.0 , respectively, to provide estimates accounting for the cooler climate during the period that the historical records represent.

To assess how much of the climatic suitable area includes tree cover above a certain percentage and were within protected areas, the outputs from the rectilinear bioclimatic envelope models were overlaid with tree cover, derived from Moderate Resolution Imaging Spectroradiometer (MODIS) Vegetation Continuous Fields from 2010 (DiMiceli et al. 2011), and protected areas in China (IUCN and UNEP-WCMC 2014).

\section{Results}

The four models with current distribution data derived from IUCN ranges (CURR1-4, Table 1) resulted in AUC values, between 0.878 and 0.900 and TSS values between 0.601 and 0.685 , indicating good predictive power. The four models with both current distribution data and historical records (HIST1-4, Table 1) resulted in AUC values, between 0.793 and 0.835 and TSS values between 0.507 and 0.576 , again indicating good predictive power. $\mathrm{AIC}_{\mathrm{C}}$ and the derived Akaike weight scored the models with the variables PANN, PDryQ, MTCQ and MTWQ, as the best models for both current data only (CURR1) as well as for current and historical data together (HIST1). For all models, the ranks of the models based on $\mathrm{AIC}_{\mathrm{C}}$ and Akaike weights were consistent with the ranks/values of AUC and to some degree also the values of TSS (Table 1).

Human population density for 2010 contributed to our the predictive power of our models, whereas HII contributed only sligthly to the predictive power of our models (see Suporting Information Appendix S3). The response curves from the Maxent model indicate that there is a negative relationship between the current distribution of snub-nosed monkeys and both of the anthropogenic variables, as the probability of presence in the Maxent prediction decreased with increasing population density and HII (see Suporting Information Appendix S3).

PANN, MTCQ or MinTCM, PDryQ and MTWQ were the variables that best explained the distribution of Rhinopithecus (all five species modelled together). This was the case when the distribution was modelled using current distribution data (derived from IUCN ranges) as well as both current distribution data and historical records. However, the variables importance changes a little between model CURR1 and HIST1. For model CURR1, using only current distribution data, the Maxent jackknife evaluation indicate that PDryQ, followed by MTCQ and MTWQ were the strongest predictors by themselves. For model HIST1, using historical data in addition to current distribution data, MTCQ, followed by PANN and PDryQ were the strongest predictors. In both models, MTCQ was the variable that decreases the gain the most when it was omitted, which indicate that it has the most information that is not explained by the other variables (Fig. 2).

The estimated responses curves in Maxent had the same tendencies between model CURR1 and HIST1, but with higher mean values for PANN, PDryQ, and MTCQ when historical records were also included (Fig. 3). Consistent with the SDM results, the range of the different environmental variables varied between the current distribution and the historical records: All species, except $R$. avunculus, today generally occur in colder areas and higher elevation than the historical records. This is also the case if the models are calibrated using the down-adjusted temperature data to better match the historical climate reference (Fig. 4, and Supporting Information Appendix S6). Rhinopithecus roxellana and $R$. bieti also generally occur in drier areas then the historical records (Fig. 4, and 

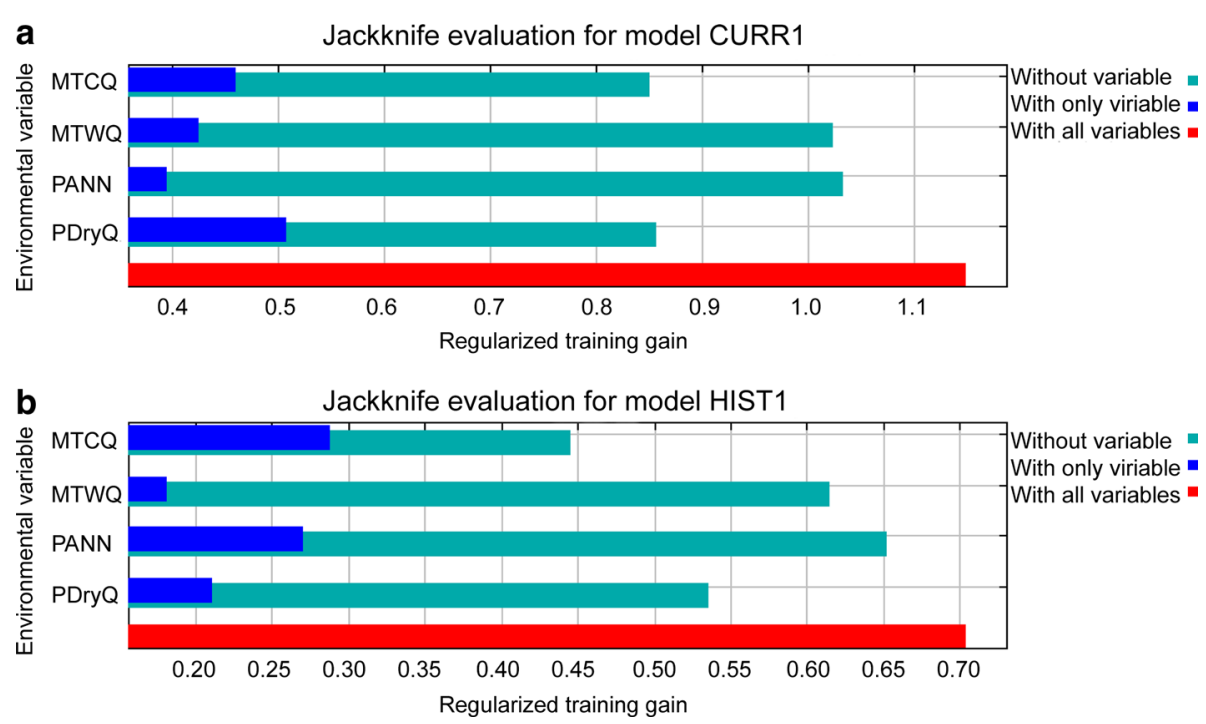

Fig. 2 Results of jackknife evaluation of the relative importance of the variables with respect to regularized training gain for (a) model CURR1 and (b) model HIST1. For acronyms see the environmental data section in methods

Supporting Information Appendix S6). The medians for all climatic variables and elevation differed between the current distribution and the historical records (Mann-Whitney $U$ tests, $\mathrm{p}<0.0001)$.

The areas predicted as climatic suitable using Maxent were $72-89 \%$ larger when historical records were also included (Fig. 5 and Table 2). The same tendencies were also obtained using rectilinear bioclimatic envelope modelling for all species together and the historical records (Fig. 6). However, the area predicted climatic suitable by the historical records in the models changed to some degree depending on which down-adjusted climate data that were used. The more down-adjusted climate data that were used, the less areas were considered climatic suitable. Primarily areas in South and South-central China were affected by the adjusted climate data (see Table 2 and Supporting Information Appendix S7 and S8 for comparison of the predicted area with the different adjusted climate data).

The Maxent results were largely consistent with the rectilinear bioclimatic envelope models for the individual species (Fig. 6). The rectilinear bioclimatic envelope analyses at the genus level and including the historical records showed, depending on the historical climate adjustment used, that between 305,800 and $319,325 \mathrm{~km}^{2}$ of the climatic suitable area in China are within protected areas, of which $95,525-100,275 \mathrm{~km}^{2}$ has tree cover $\geq 50 \%$ and $17,1775-17550 \mathrm{~km}^{2}$ has $\geq 75 \%$ tree cover. In addition, there are between 738,425 and $824,425 \mathrm{~km}^{2}$ outside protected areas but with tree cover $\geq 50 \%$ and of these $57,350-62,100 \mathrm{~km}^{2}$ has tree cover $\geq 75 \%$ (Fig. 7 and Table 2, and Supporting Information Appendix S9). 

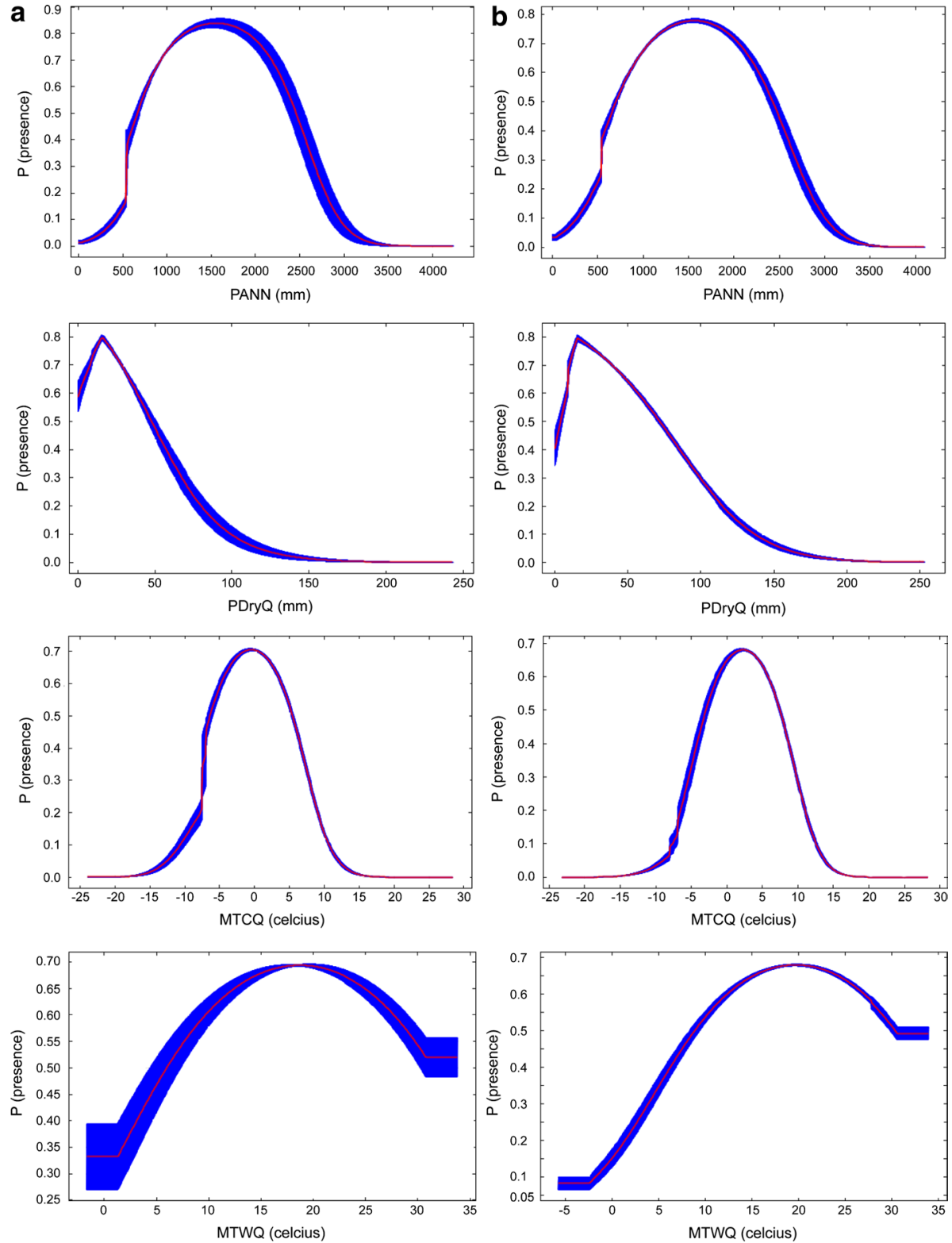

Fig. 3 Estimated response curves (logistic output: probability of presence), which show how the logistic prediction changes as each environmental variable is varied, keeping all other environmental variables at their average sample value, for (a) model CURR1 and (b) model HIST1. For acronyms see the environmental data section in methods

\section{Discussion}

One or more species of Rhinopithecus were recently more widely distributed in China. All species are today confined to fragmented areas with declining populations and are listed 
Fig. 4 Boxplot of elevation (ELEV), mean temperature of coldest quarter (MTCQ) and precipitation during driest quarter (PDryQ) for the historical records, the IUCN ranges (all five species together) and for the five species separately. See Supplementary Information Appendix S3 for boxplot of PANN, MinTCM and MTWQ. MTCQ for the historical records is divided into four categories; current climate data without adjustments, current climate data adjusted with $-0.7,-1.5$, and $-2.0^{\circ} \mathrm{C}$, respectively

as endangered or critically endangered on the IUCN Red List (Bleisch et al. 2008; Bleisch and Richardson 2008; Xuan Canh et al. 2008; Yongcheng and Richardson 2008; Geissmann et al. 2012) and at least three of the species are, with total population sizes under 1000 individuals, close to extinction. In this study, we assessed three key questions for the conservation of Rhinopithecus: which climatic variables determine the current distribution of this genus, to what extent has the niche space of the genus been truncated due to anthropogenic activities, and what is the potential distribution of the genus, using species distribution modelling (SDM) with both current and historical distribution data. All the models scored AUC values between 0.793 and 0.900 and TSS values between 0.507 and 0.685 , indicating good predictive power. PANN, MTCQ, MinTCM, PDryQ, and MTWQ were the variables that best explained the distribution of Rhinopithecus. There is a clear trend that the historical records generally are from areas that are warmer, wetter, and in lower elevation then the current distribution records (except the ones from $R$. avunculus), indicating extensive niche truncation. This is the case regardless of whether the current climate data were down-adjusted by $-0.7,-1.5$, or $-2.0{ }^{\circ} \mathrm{C}$. As such, models that included historical records projected climatically suitable habitat to occupy a larger geographic extent than models calibrated only with IUCN range data. This is the case using Maxent as well as rectilinear bioclimatic envelope modelling with different adjusted climate data. Based on the later, $74,525-79,650 \mathrm{~km}^{2}$ of the climatically suitable area has tree cover $\geq 75 \%$ and could therefore constitute suitable habitat for Rhinopithecus, hereof $17,175-17,550 \mathrm{~km}^{2}$ within protected areas. All Rhinopithecus species inhabit primary forest and grid cells with tree cover $\geq 75 \%$ might constitute important potential habitat. In addition, an additional $834,950-924,700 \mathrm{~km}^{2}$ climatically suitable area has tree cover between 50 and $75 \%$, hereof $96,525-100,275 \mathrm{~km}^{2}$ within protected areas. This area may also be suitable ecologically, as Rhinopithecus species have been observed spending a considerable time on the ground feeding on fallen nuts, ground plants etc. (Long et al. 1994; Xiang et al. 2007b, 2012; Grueter et al. 2009a).

The accuracy of the modelling depends on the accuracy of the distribution data. A problem with accuracy of the distribution data may occur as the IUCN distribution polygons (IUCN 2014) we used as a basis for our current records undoubtedly include areas that are not currently inhabited by Rhinopithecus and may include areas that are outside the current realized climatic niche of the species. However, we reduce the risk of including areas beyond the current realized niche by excluding grid cells that are outside of the known elevation range of the genus, have low tree cover, or have high human population densities or human influence. Another problem regarding the possible inclusion of climate outside the current realized climatic niche of the species in the analyses is that we modelled all species together. However, the historical records could not be identified into species level and we can also see in the rectilinear bioclimatic envelope models for the individual species that it does not affect the overall result as they are in accordance with the rectilinear bioclimatic envelope model of the genus. Additionally, at least some of the Rhinopithecus species live in a fairly wide range of climates and have high dietary plasticity (Long et al. 1994; Yiming 2006; Guo et al. 2007; Grueter et al. 2009a; Xiang et al. 2007b, 2012; Wong 

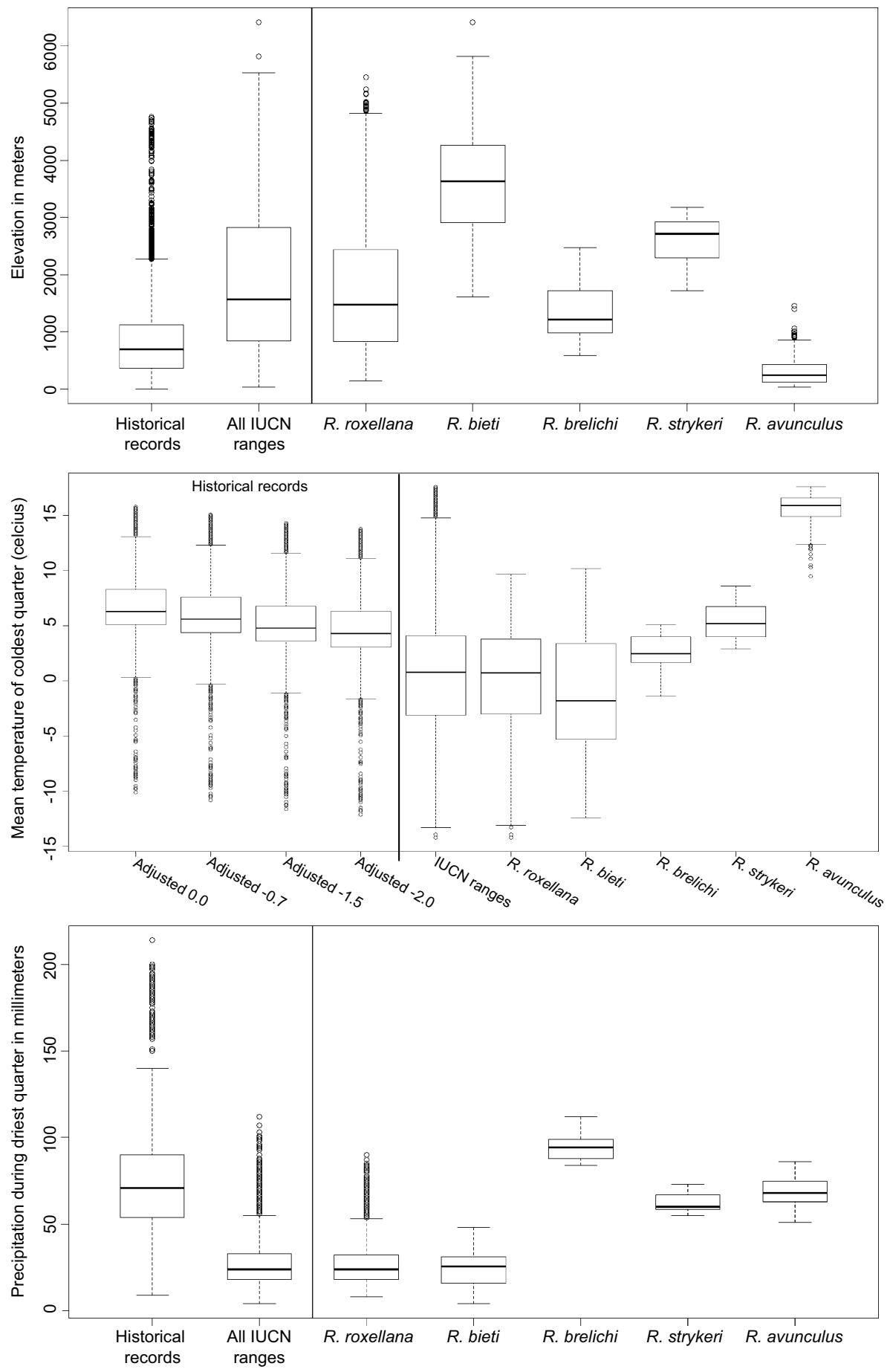

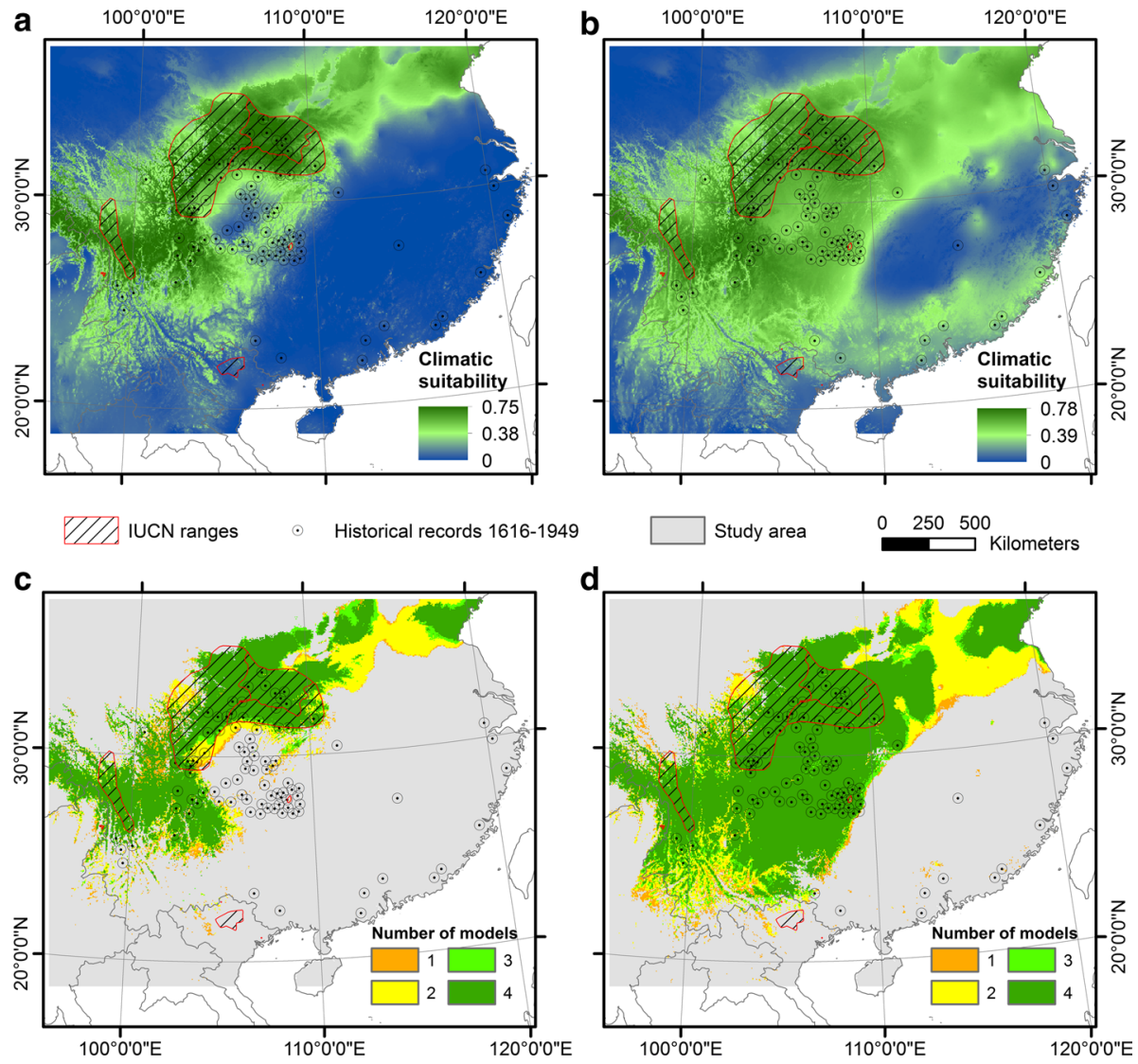

Fig. 5 Mean climatic suitability and predicted climatic distribution using ensemble intersection and the 10th percentile training presence threshold for the $2 \times 4$ models (Table 1) at a $5 \mathrm{~km} \times 5 \mathrm{~km}$ resolution. a Mean climatic suitability using only current range data and $\mathbf{b}$ using both current and historical data from 1616 to 1949 . c Ensemble intersection for model CURR1-4 using only current range data and d for model HIST1-4 using both current and historical data from 1616 to 1949. Colours indicate number of models (ranging from 1 to 4 ) predicting values for climatic suitability above the 10th percentile training presence threshold. No colour within the study area indicates that none of the models predicted values for climatic suitability above the 10th percentile training presence threshold

et al. 2013). Moreover, both the Maxent and the rectilinear bioclimatic envelope model is in accordance with the ecoregions, which distributions have been similar from the earliest historical records used (1616) to present (Ni et al. 2014) (see Supporting Information Appendix S1).

Another aspect worth discussing is that China experienced a cold period between 1321 and 1920 (Ge et al. 2013), which to some extent coincides with the disappearance of Rhinopithecus in southeast China. However, it does not make ecological sense that Rhinopithecus should retreat to higher elevations and hence even colder conditions during a period of increased cold. If temperature changes had affected its range dynamics in this period, Rhinopithecus would logically have been expected to retreat to warmer areas, or first retreat to the colder areas after 1920 when the current warm period began, i.e., both scenarios in contrast to the observed pattern. Furthermore, Rhinopithecus also lived in southeast China during the last warm period before 1321 . 


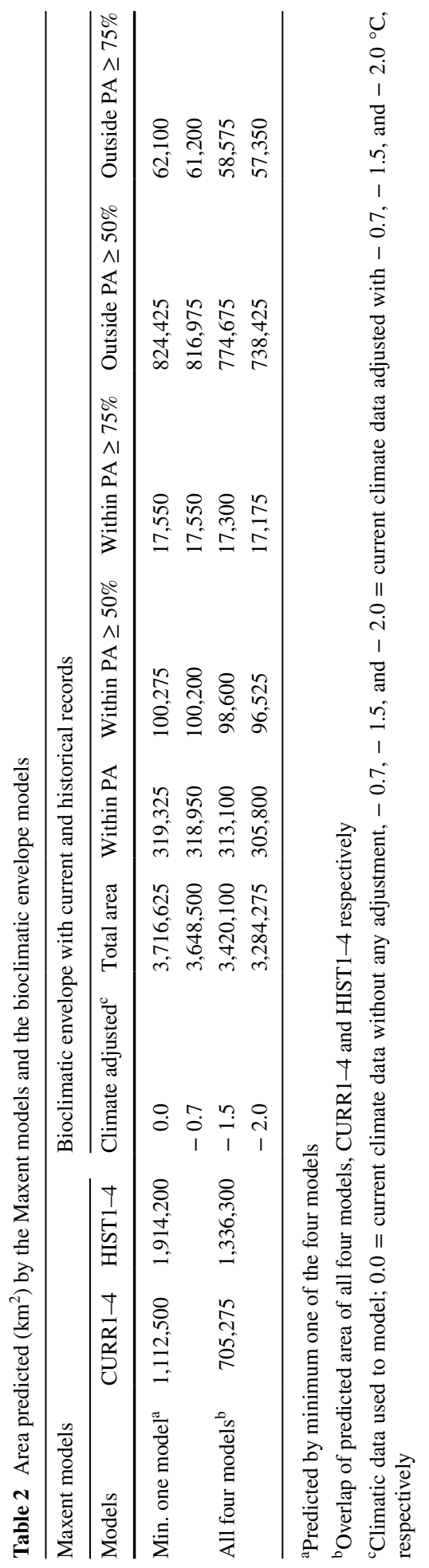



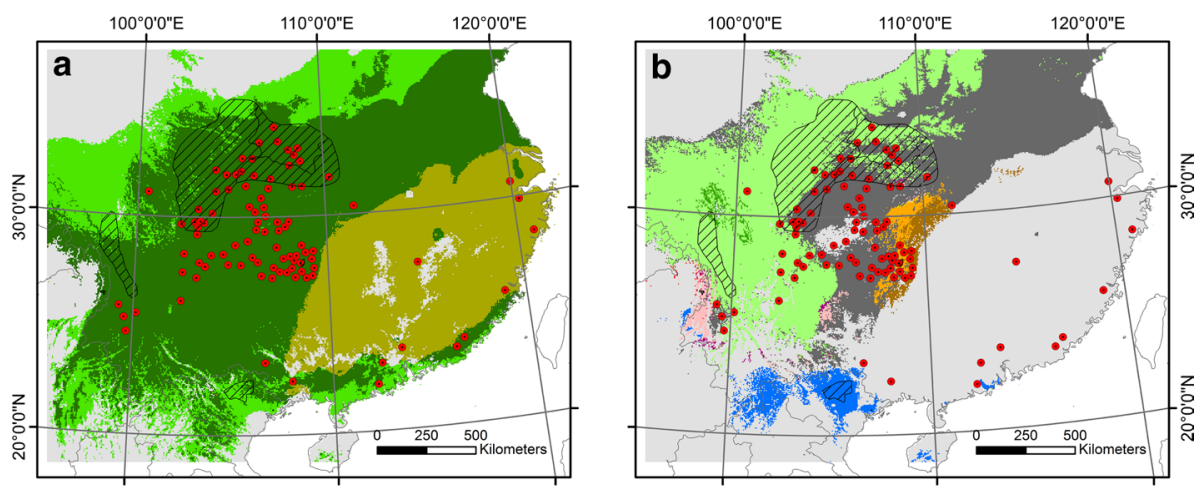

UIII工 IUCN ranges (all species)

- Historical records $1616-1949$

Study area

Climatic suitability (only historical records)

Climatic suitability (only current records)

Climatic suitability (both current and historical records)

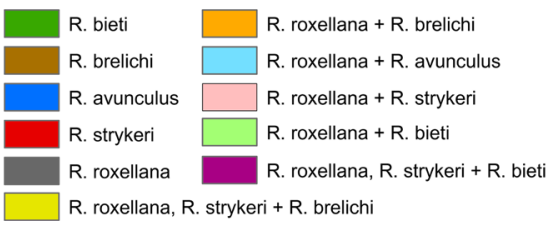

Fig. 6 Climatic suitable area, defined as area within minimum and maximum values of the five climatic variables, PANN, PDryQ, MinTCM, MTCQ and MTWQ, at a $5 \mathrm{~km} \times 5 \mathrm{~km}$ resolution. a Model for all five species together, using only current data from IUCN ranges (light and dark green) and area included if historical records is also used (brown green). Temperature data for historical records are adjusted with $-0.7{ }^{\circ} \mathrm{C}$ (see Supporting Information Appendix S7 for other climate adjustments). b Climatic suitable area, defined as area within minimum and maximum values of the five climatic variables, PANN, PDryQ, MinTCM, MTCQ and MTWQ, at a $5 \mathrm{~km} \times 5 \mathrm{~km}$ resolution for each species separately and the overlap between them

Our analyses strongly suggest that the Rhinopithecus species now survive as refugee species sensu Cromsigt et al. (2012). Comparing the SDM results with and without the historical records show that there clearly has been truncation of the occupied environmental space with respect to temperature and precipitation. The historical records are generally from warmer and wetter areas, and in lower elevation than the current distribution. This is also the reason why most of South, Southeast and Central China, which is warmer and wetter than the areas where the species is found today, only is predicted as climatic suitable if the historical records are included in the analyses. Hence, the reason why a large area in Southeast China is not predicted as suitable for Rhinopithecus, when only current distribution data is used, is mainly due to too high levels of precipitation, likely reflecting that high-rainfall areas have historically been more suitable for agriculture and human settlement, with the disappearance of Rhinopithecus from these areas synchronous with a rapid increase in human population and cultivated areas here during the last 400 years (Durand 1960; Li et al. 2002). In contrast, we are not aware of any plausible mechanisms whereby high rainfall would exclude Rhinopithecus directly or via non-anthropogenic indirect effects. Today, Rhinopithecus are largely restricted to higher elevations than much of their historical distribution. Li et al. (2002) provide evidence that Rhinopithecus was first extirpated from lower elevation during the last 400 years. Higher elevation areas are more remote and difficult for humans to access and utilize and other studies have found less deforestation, more reforestation and afforestation, less range contraction, and less 


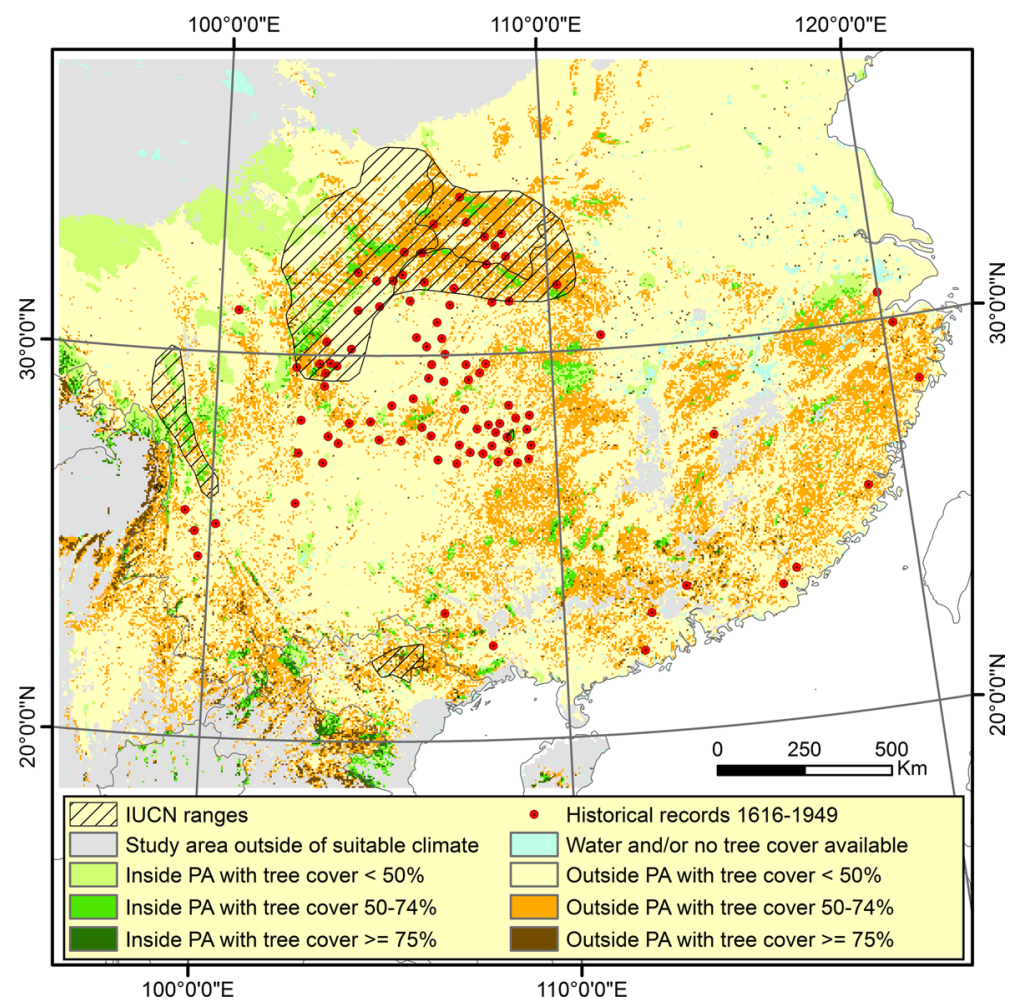

Fig. 7 Climatic suitable area as defined in Fig. 6 outside protected areas (PA) (sand colors) and within protected areas (PA) (green colors). The darker sand or green color the higher tree cover percentage

extinction in topographically steep areas (Laliberte and Ripple 2004; Fisher 2011; Sandel and Svenning 2013; Faurby and Svenning 2015; Nüchel and Svenning 2017). Furthermore, many other species in the region, e.g., giant panda (Ailuropoda melanoleuca) and red panda (Ailurus fulgens), have also been impacted by strong anthropogenic pressure during the recent centuries with population declines and range retractions as consequences (Ceballos and Ehrlich 2002; Zhu et al. 2010; Hu et al. 2011). As such, it is likely that Rhinopithecus have been locally extirpated by anthropogenic factors, and are now restricted to areas with higher elevation and which are less accessible, even though these may be suboptimal habitats. Hence, Rhinopithecus is likely a refugee taxon, living in an anthropogenic truncated niche space.

Even though our results show that there are large areas that are climatic suitable for the genus, have tree cover between 50 and $75 \%$ or above $75 \%$, and some even protected, it does not mean that the species can actually live in these areas. For example, our modelling does not show whether or not the vegetation meets the different Rhinopithecus species' specific requirements in terms of food and habitat structure. Today, $R$. avunculus is found in tropical evergreen (Xuan Canh et al. 2008). Rhinopithecus brelichi is found in mixed deciduous and evergreen broadleaf (Bleisch et al. 2008; Xiang et al. 2009). Rhinopithecus roxellana and $R$. strykeri is found in mixed deciduous and evergreen broadleaf and mixed coniferbroadleaf forest (Guo et al. 2007; Yongcheng and Richardson 2008; Chi et al. 2014), and 
R. bieti is found in high-altitude evergreen forest (Long et al. 1994; Bleisch and Richardson 2008; Xiang et al. 2011). They are all folivorous, but also feed on fruits, seeds, insects and lichens is also an important part of the diet for $R$. roxellana and especially $R$. bieti (Kirkpatrick 1995; Quyet et al. 2007; Guo et al. 2007; Xuan Canh et al. 2008; Grueter et al. 2009a, b; Xiang et al. 2012). In addition, some if not many of the protected areas might be so-called "paper parks", where no or little management and law enforcement is done (Harkness 1998; Joppa et al. 2008), meaning that they offer little to no real protection. This is particularly a problem in relation to that poaching and illegal timber extraction threatens many of the extant populations (Xiao et al. 2003; Xiang et al. 2007a, 2009; Hoang 2010). Moreover, many areas have high anthropogenic pressure, e.g., in terms of human populations densities, agriculture and many suitable areas will be unreachable for Rhinopithecus due to natural and anthropogenic dispersal barriers such as rivers, urban areas and agricultural land (Liu et al. 2009; Chang et al. 2012). Other studies which have tried to model the potential distribution of species have also emphasised the importance of taking anthropogenic pressure into account (Kuemmerle et al. 2011; Escobar et al. 2015). In our study, human population density contributed to the predictive power of our models, while HII contributed little. The reason why HII has little effect on our models more is likely due to the coarse scale of our data but also the fact that there indeed is high anthropogenic pressure within some of the species current ranges (Xiang et al. 2009). In addition, the large reforestation and afforestation programs in China, might offer great opportunities in connection with the above mentioned concerns about habitat requirements, dispersal barriers and anthropogenic pressure (Yin et al. 2005).

SDMs are frequently used to assess which variables influence the distribution of a taxa, and to identify its potential distribution. This makes SDMs particularly useful for conservation management. However, SDMs often rest on the assumption that the current realized niche more or less represents the fundamental niche. Many species have been locally extirpated by anthropogenic pressure and if SDMs does not take this into account and only use current distribution data to model the potential distribution they might not show the "true picture" of a species tolerance to e.g. climate. Our models are coarse, but like other studies, e.g. Chatterjee et al. (2012), they emphasise the importance in the use of historical records/ distribution data for mapping the potential distribution of species. This is especially of the utmost importance in conservation studies, where e.g. the influence from climate change and reintroduction potential is being modelled for threatened species, which might be refugee species living in an anthropogenically truncated niche space.

Much is still not known about the ecology of Rhinopithecus and as stated in the introduction they face an uncertain future. To enhance the survival prospects of Rhinopithecus, populations and distributions should be increased, and it is of utmost importance to learn more about their ecology and habitat requirements, protect existing and potential habitat, make habitat corridors and investigate the possibilities for assisted migration. Our results show that there is likely much potential for expanding some of the Rhinopithecus species' distribution to parts of the former range of the genus, and they can be used as a basis to further investigate which areas that might be used for reintroduction of Rhinopithecus or to connect existing populations through habitat corridors.

Acknowledgements JCS was supported by the European Research Council (ERC-2012-StG-310886HISTFUNC) and also considers this work a contribution to his VILLUM Investigator project (VILLUM FONDEN, Grant 16549). 
Open Access This article is distributed under the terms of the Creative Commons Attribution 4.0 International License (http://creativecommons.org/licenses/by/4.0/), which permits unrestricted use, distribution, and reproduction in any medium, provided you give appropriate credit to the original author(s) and the source, provide a link to the Creative Commons license, and indicate if changes were made.

\section{References}

Allouche O, Tsoar A, Kadmon R (2006) Assessing the accuracy of species distribution models: prevalence, kappa and the true skill statistic (TSS). J Appl Ecol 43:1223-1232. https://doi.org/10.1111/j.1365 -2664.2006.01214.x

Bean WT, Stafford R, Brashares JS (2012) The effects of small sample size and sample bias on threshold selection and accuracy assessment of species distribution models. Ecography 35:250-258. https://doi. org/10.1111/j.1600-0587.2011.06545.x

Bleisch W, Richardson M (2008) Rhinopithecus bieti. The IUCN red list of threatened species 2008: e.T19597A8986243. http://dx.doi.org/10.2305/IUCN.UK.2008.RLTS.T19597A8986243.en

Bleisch W, Yongcheng L, Richardson M (2008) Rhinopithecus brelichi. The IUCN red list of threatened species 2008: e.T19595A8985249. http://dx.doi.org/10.2305/IUCN.UK.2008.RLTS.T19595A89852 49.en

Braunisch V, Bollmann K, Graf RF, Hirzel AH (2008) Living on the edge-modelling habitat suitability for species at the edge of their fundamental niche. Ecol Model 214:153-167. https://doi.org/10.1016/j.ecol model.2008.02.001

Cao Y, DeWalt RE, Robinson JL et al (2013) Using Maxent to model the historic distributions of stonefly species in Illinois streams: the effects of regularization and threshold selections. Ecol Model 259:3039. https://doi.org/10.1016/j.ecolmodel.2013.03.012

Caughley G (1994) Directions in conservation biology. J Anim Ecol 63:215-244. https://doi.org/10.2307 15542

Ceballos G, Ehrlich PR (2002) Mammal population losses and the extinction crisis. Science 296:904-907. https://doi.org/10.1126/science.1069349

Center for International Earth Science Information Network-CIESIN-Columbia University (2015) gridded population of the world, version 4 (GPWv4): population density adjusted to match 2015 revision of UN WPP country totals

Chang ZF, Luo MF, Liu ZJ et al (2012) Human influence on the population decline and loss of genetic diversity in a small and isolated population of Sichuan snub-nosed monkeys (Rhinopithecus roxellana). Genetica 140:105-114. https://doi.org/10.1007/s10709-012-9662-9

Chatterjee HJ, Tse JSY, Turvey ST (2012) Using ecological niche modelling to predict spatial and temporal distribution patterns in Chinese gibbons: lessons from the present and the past. Folia Primatol 83:8599. https://doi.org/10.1159/000342696

Chi M, Zhi-Pang H, Xiao-Fei Z et al (2014) Distribution and conservation status of Rhinopithecus strykeri in China. Primates 55:377-382. https://doi.org/10.1007/s10329-014-0425-3

Cromsigt JPGM, Kerley GIH, Kowalczyk R (2012) The difficulty of using species distribution modelling for the conservation of refugee species - the example of European bison. Divers Distrib 18:1253-1257. https://doi.org/10.1111/j.1472-4642.2012.00927.x

DiMiceli CM, Carroll ML, Sohlberg RA et al (2011) Annual global automated MODIS vegetation continuous fields (MOD44B) at $250 \mathrm{~m}$ spatial resolution for data years beginning day 65, 2000-2010, collection 5 Percent Tree Cover. University of Maryland, College Park

Durand JD (1960) The population statistics of China, A.D. 2-1953. Popul Stud 13:209-256. https://doi. org/10.1002/ajpa.10126

Elith J, Graham CH, Anderson RP et al (2006) Novel methods improve prediction of species' distributions from occurrence data. Ecography 29:129-151. https://doi.org/10.1111/j.2006.0906-7590.04596.x

Elith J, Phillips SJ, Hastie T et al (2011) A statistical explanation of MaxEnt for ecologists. Divers Distrib 17:43-57. https://doi.org/10.1111/j.1472-4642.2010.00725.x

Escobar LE, Awan MN, Qiao H (2015) Anthropogenic disturbance and habitat loss for the red-listed Asiatic black bear (Ursus thibetanus): using ecological niche modeling and nighttime light satellite imagery. Biol Conserv 191:400-407. https://doi.org/10.1016/j.biocon.2015.06.040

Faurby S, Svenning J-C (2015) Historic and prehistoric human-driven extinctions have reshaped global mammal diversity patterns. Divers Distrib 21:1155-1166. https://doi.org/10.1111/ddi.12369

Fisher DO (2011) Trajectories from extinction: where are missing mammals rediscovered? Glob Ecol Biogeogr 20:415-425. https://doi.org/10.1111/j.1466-8238.2010.00624.x 
Freeman EA, Moisen GG (2008) A comparison of the performance of threshold criteria for binary classification in terms of predicted prevalence and kappa. Ecol Model 217:48-58. https://doi.org/10.1016 /j.ecolmodel.2008.05.015

Ge Q, Hao Z, Zheng J, Shao X (2013) Temperature changes over the past $2000 \mathrm{yr}$ in China and comparison with the Northern Hemisphere. Clim Past 9:1153-1160. https://doi.org/10.5194/cp-9-1153-2013

Geissmann T, Momberg F, Whitten T (2012) Rhinopithecus strykeri. The IUCN red list of threatened species 2012: e.T13508501A13508504. http://dx.doi.org/10.2305/IUCN.UK.2012-1.RLTS.T1350850 1A13508504.en

Grueter CC, Li D, Ren B et al (2009a) Dietary profile of Rhinopithecus bieti and its socioecological implications. Int J Primatol 30:601-624. https://doi.org/10.1007/s10764-009-9363-0

Grueter CC, Li D, Ren B et al (2009b) Fallback foods of temperate-living primates: a case study on snubnosed monkeys. Am J Phys Anthropol 140:700-715. https://doi.org/10.1002/ajpa.21024

Guo S, Li B, Watanabe K (2007) Diet and activity budget of Rhinopithecus roxellana in the Qinling Mountains, China. Primates 48:268-276. https://doi.org/10.1007/s10329-007-0048-z

Harkness J (1998) Recent trends in forestry and conservation of biodiversity in China. China Q 156:911. https://doi.org/10.1017/S0305741000051390

Hijmans RJ, Cameron SE, Parra JL et al (2005) Very high resolution interpolated climate surfaces for global land areas. Int J Climatol 25:1965-1978. https://doi.org/10.1002/joc.1276

Hoang TM (2010) Semi-annual report-ensuring the survival of Tonkin snub-nosed monkey (Rhinopithecus Avunculus) in Na Hang nature reserve, Tuyen Quang Province, Northeastern Vietnam. Rufford foundation, London

Hoffmann M, Hilton-Taylor C, Angulo A et al (2010) The impact of conservation on the status of the world's vertebrates. Science 330:1503-1509. https://doi.org/10.1126/science.1194442

Hu Y, Guo Y, Qi D et al (2011) Genetic structuring and recent demographic history of red pandas (Ailurus fulgens) inferred from microsatellite and mitochondrial DNA. Mol Ecol 20:2662-2675. https://doi. org/10.1111/j.1365-294X.2011.05126.X

IUCN (2008) An analysis of mammals on the 2008 IUCN red list. IUCN, Conservation International, Arizona State University, Texas A\&M University, University of Rome, University of Virginia, Zoological Society London. 2008

IUCN (International Union for Conservation of Nature) (2014) The IUCN red list of threatened species. Version 2014.2. http://www.iucnredlist.org

IUCN (International Union for Conservation of Nature) (2016) The IUCN red list of threatened species. Version 2016-3. http://www.iucnredlist.org

IUCN, UNEP-WCMC (2014) The world database on protected areas (WDPA). Cambridge, UK: UNEPWCMC. www.protectedplanet.net. Accessed 16 Jan 2015

Jarvis A, Reuter HI, Nelson A, Guevara E (2008) Hole-filled SRTM for the globe version 4, available from the CGIAR-CSI SRTM 90m Database. http://srtm.csi.cgiar.org

Jiménez-Valverde A, Lobo JM (2007) Threshold criteria for conversion of probability of species presence to either-or presence-absence. Acta Oecol 31:361-369. https://doi.org/10.1016/j.actao.2007.02.001

Joppa LN, Pfaff A (2011) Global protected area impacts. Proc R Soc Lond B 278:1633-1638. https://doi. org/10.1098/rspb.2010.1713

Joppa LN, Loarie SR, Pimm SL (2008) On the protection of "protected areas". Proc Natl Acad Sci 105:6673-6678. https://doi.org/10.1073/pnas.0802471105

Juffe-Bignoli D, Burgess ND, Bingham H et al (2014) Protected planet report 2014. UNEP-WCMC, Cambridge

Kerley GIH, Kowalczyk R, Cromsigt JPGM (2012) Conservation implications of the refugee species concept and the European bison: king of the forest or refugee in a marginal habitat? Ecography 35:519529. https://doi.org/10.1111/j.1600-0587.2011.07146.x

Kirkpatrick RC (1995) The natural history and conservation of the snub-nosed monkeys (genus Rhinopithecus). Biol Cons 72:363-369. https://doi.org/10.1016/0006-3207(94)00039-S

Kuemmerle T, Radeloff VC, Perzanowski K et al (2011) Predicting potential European bison habitat across its former range. Ecol Appl 21:830-843. https://doi.org/10.1890/10-0073.1

Laliberte AS, Ripple WJ (2004) Range contractions of North American carnivores and ungulates. Bioscience 54:123-138. https://doi.org/10.1641/0006-3568(2004)

Li B, Pan R, Oxnard C (2002) Extinction of snub-nosed monkeys in China during the past 400 Years. Int J Primatol 23:1227-1244. https://doi.org/10.1023/A:1021122819845

Liu J, Diamond J (2005) China's environment in a globalizing world. Nature 435:1179-1186. https://doi. org/10.1038/4351179a

Liu C, Berry PM, Dawson TP, Pearson RG (2005) Selecting thresholds of occurrence in the prediction of species distributions. Ecography 28:385-393. https://doi.org/10.1111/j.0906-7590.2005.03957.x 
Liu Z, Ren B, Wu R et al (2009) The effect of landscape features on population genetic structure in Yunnan snub-nosed monkeys (Rhinopithecus bieti) implies an anthropogenic genetic discontinuity. Mol Ecol 18:3831-3846. https://doi.org/10.1111/j.1365-294X.2009.04330.x

Liu C, White M, Newell G (2013) Selecting thresholds for the prediction of species occurrence with presence-only data. J Biogeogr 40:778-789. https://doi.org/10.1111/jbi.12058

Lobo JM, Jiménez-Valverde A, Real R (2008) AUC: a misleading measure of the performance of predictive distribution models. Glob Ecol Biogeogr 17:145-151. https://doi.org/10.1111/j.1466-8238.2007.0035 8.X

Long YC, Kirkpatrick RC, Zhong T, Xiao L (1994) Report on the distribution, population, and ecology of the yunnan snub-nosed monkey (Rhinopithecus bieti). Primates 35:241-250. https://doi.org/10.1007/ bf02382060

Morueta-Holme N, Fløjgaard C, Svenning J-C (2010) Climate change risks and conservation implications for a threatened small-range mammal species. PLoS ONE 5:e10360. https://doi.org/10.1371/journal. pone. 0010360

Muscarella R, Galante PJ, Soley-Guardia M et al (2014) ENMeval: an R package for conducting spatially independent evaluations and estimating optimal model complexity for Maxent ecological niche models. Methods Ecol Evol 5:1198-1205. https://doi.org/10.1111/2041-210X.12261

Naundrup PJ, Svenning J-C (2015) A geographic assessment of the global scope for rewilding with wildliving horses (Equus ferus). PLoS ONE 10:e0132359. https://doi.org/10.1371/journal.pone.0132359

Ni J, Cao X, Jeltsch F, Herzschuh U (2014) Biome distribution over the last 22,000 yr in China. Palaeogeogr Palaeoclimatol Palaeoecol 409:33-47. https://doi.org/10.1016/j.palaeo.2014.04.023

Nüchel J, Svenning J-C (2017) Recent tree cover increases in eastern China linked to low, declining human pressure, steep topography, and climatic conditions favoring tree growth. PLoS ONE 12:e177552. https://doi.org/10.1371/journal.pone.0177552

Olson DM, Dinerstein E, Wikramanayake ED et al (2001) Terrestrial ecoregions of the world: a new map of life on earth. Bioscience 51:933-938

Pearson RG, Dawson TP, Liu C (2004) Modelling species distributions in Britain: a hierarchical integration of climate and land-cover data. Ecography 27:285-298. https://doi.org/10.1111/j.0906-7590.2004 $.03740 . \mathrm{x}$

Peng S-S, Piao S, Zeng Z et al (2014) Afforestation in China cools local land surface temperature. Proc Natl Acad Sci 111:2915-2919. https://doi.org/10.1073/pnas.1315126111

Phillips SJ, Dudík M (2008) Modeling of species distributions with Maxent: new extensions and a comprehensive evaluation. Ecography 31:161-175. https://doi.org/10.1111/j.0906-7590.2008.5203.x

Phillips SJ, Anderson RP, Schapire RE (2006) Maximum entropy modeling of species geographic distributions. Ecol Model 190:231-259. https://doi.org/10.1016/j.ecolmodel.2005.03.026

Quyet LK, Duc NA, Tai VA et al (2007) Diet of the Tonkin snub-nosed monkey (Rhinopithecus avunculus) in the Khau Ca area, Ha Giang Province, Northeastern Vietnam. Vietnam J Primatol 1:75-83

Sandel B, Svenning J-C (2013) Human impacts drive a global topographic signature in tree cover. Nat Commun 4:1-7. https://doi.org/10.1038/ncomms3474

Schipper J, Chanson JS, Chiozza F et al (2008) The status of the world's land and marine mammals: diversity, threat, and knowledge. Science 322:225-230. https://doi.org/10.1126/science.1165115

Seddon PJ, Griffiths CJ, Soorae PS, Armstrong DP (2014) Reversing defaunation: restoring species in a changing world. Science 345:406-412. https://doi.org/10.1126/science.1251818

Smith AT, Xie Y (2008) A guide to the mammals of China. Princeton University Press, Princeton

Svenning J-C, Pedersen PBM, Donlan J et al (2016) Science for a wilder Anthropocene -synthesis and future directions for rewilding research. Proc Natl Acad Sci 113:898-906. https://doi.org/10.1073/pnas .1502556112

Verbruggen H (2012) OccurrenceThinner version 1.04. http://www.phycoweb.net/software

Verbruggen H, Tyberghein L, Belton GS et al (2013) Improving transferability of introduced species' distribution models: new tools to forecast the spread of a highly invasive seaweed. PLoS ONE 8:1-13. http s://doi.org/10.1371/journal.pone.0068337

Warren DL, Seifert SN (2010) Ecological niche modeling in Maxent: the importance of model complexity and the performance of model selection criteria. Ecol Appl 21:335-342. https://doi.org/10.1890/101171.1

Warren DL, Glor RE, Turelli M (2008) Environmental niche equivalency versus conservatism: quantitative approaches to niche evolution. Evolution 62:2868-2883. https://doi.org/10.1111/j.1558-5646.2008 .00482.x

Warren DL, Glor RE, Turelli M (2010) ENMTools: a toolbox for comparative studies of environmental niche models. Ecography 33:607-611. https://doi.org/10.1111/j.1600-0587.2009.06142.x 
Wildlife Conservation Society-WCS-and Center for International earth science information networkCIESIN-Columbia University (2005) Last of the Wild Project, Version 2, 2005 (LWP-2): Global Human Influence Index (HII) Dataset (IGHP)

Wong MHG, Li R, Xu M, Long Y (2013) An integrative approach to assessing the potential impacts of climate change on the Yunnan snub-nosed monkey. Biol Conserv 158:401-409. https://doi.org/10.1016 /j.biocon.2012.08.030

Xiang Z-F, Huo S, Wang L et al (2007a) Distribution, status and conservation of the black-and-white snubnosed monkey Rhinopithecus bieti in Tibet. Oryx 41:525-531. https://doi.org/10.1017/S00306053070 12124

Xiang Z-F, Huo S, Xiao W et al (2007b) Diet and feeding behavior of Rhinopithecus bieti at Xiaochangdu, Tibet: adaptations to a marginal environment. Am J Primatol 69:1141-1158. https://doi.org/10.1002/ ajp. 20412

Xiang Z-F, Nie S-G, Lei X-P et al (2009) Current status and conservation of the gray snub-nosed monkey Rhinopithecus brelichi (Colobinae) in Guizhou, China. Biol Conserv 142:469-476. https://doi. org/10.1016/j.biocon.2008.11.019

Xiang Z-FF, Huo S, Xiao W (2011) Habitat selection of black-and-white snub-nosed monkeys (Rhinopithecus bieti) in Tibet: implications for species conservation. Am J Primatol 73:347-355. https://doi. org/10.1002/ajp.20901

Xiang Z-F, Liang W-B, Nie S-G, Li M (2012) Diet and feeding behavior of Rhinopithecus brelichi at Yangaoping, Guizhou. Am J Primatol 74:551-560. https://doi.org/10.1002/ajp.22008

Xiao W, Ding W, Cui L-W et al (2003) Habitat degradation of Rhinopithecus bieti in Yunnan, China. Int J Primatol 24:389-398. https://doi.org/10.1023/A:1023009518806

Xuan Canh L, Khac Queyt L, Thanh Hai D, Boonratana R (2008) Rhinopithecus avunculus. The IUCN red list of threatened species 2008: e.T19594A8984679. http://dx.doi.org/10.2305/IUCN.UK.2008.RLTS .T19594A8984679.en

Yiming L (2006) Seasonal variation of diet and food availability in a group of Sichuan snub-nosed monkeys in Shennongjia Nature Reserve, China. Am J Primatol 68:217-233. https://doi.org/10.1002/ajp.20220

Yin R, Xu J, Li Z, Liu C (2005) China's ecological rehabilitation: the unprecedented efforts and dramatic impacts of reforestation and slope protection in western China. China Environ Ser 7:17-32

Yongcheng L, Richardson M (2008) Rhinopithecus roxellana. The IUCN red list of threatened species 2008: e.T19596A8985735. http://dx.doi.org/10.2305/IUCN.UK.2008.RLTS.T19596A8985735.en

Zhang Y, Song C (2006) Impacts of afforestation, deforestation, and reforestation on forest cover in China from 1949 to 2003. J For 104:383-387

Zhu L, Zhan X, Wu H et al (2010) Conservation implications of drastic reductions in the smallest and most isolated populations of giant pandas. Conserv Biol 24:1299-1306. https://doi.org/10.1111/j.1523-1739 .2010.01499.x 